\title{
Serum lactate dehydrogenase and survival following cancer diagnosis
}

\begin{abstract}
Wahyu Wulaningsih*,1, Lars Holmberg ${ }^{1,2,3}$, Hans Garmo ${ }^{1,3}$, Håkan Malmstrom ${ }^{4}$, Mats Lambe ${ }^{3,5}$, Niklas Hammar ${ }^{4,6}$, Göran Walldius ${ }^{7}$, Ingmar Jungner ${ }^{8}$, Tony $\mathrm{Ng}^{9}$ and Mieke Van Hemelrijck ${ }^{1,4}$

${ }^{1}$ Division of Cancer Studies, Cancer Epidemiology Group, King's College London, Research Oncology, 3rd Floor, Bermondsey Wing, Guy's Hospital, London SE1 9RT, UK; ${ }^{2}$ Department of Surgical Sciences, Uppsala University Hospital, Uppsala 751 85, Sweden; ${ }^{3}$ Regional Cancer Centre, Uppsala 751 85, Sweden; ${ }^{4}$ Department of Epidemiology, Institute of Environmental Medicine, Karolinska Institutet, Stockholm 171 77, Sweden; ${ }^{5}$ Department of Medical Epidemiology and Biostatistics, Karolinska Institutet, Stockholm 171 77, Sweden; ${ }^{6}$ AstraZeneca R\&D, Mölndal 431 50, Sweden; ${ }^{7}$ Department of Cardiovascular Epidemiology, Institute of Environmental Medicine, Karolinska Institutet, Stockholm 171 77, Sweden; ${ }^{8}$ Department of Medicine, Clinical Epidemiological Unit, Karolinska Institutet and CALAB Research, Stockholm 171 77, Sweden and ${ }^{9}$ Richard Dimbleby Department of Cancer Research, Randall Division and Division of Cancer Studies, King's College London, London SE1 1UL, UK
\end{abstract}

Background: There is evidence that high level of serum lactate dehydrogenase $(L D H)$ is associated with poorer overall survival in several malignancies, but its link to cancer-specific survival is unclear.

Methods: A total of 7895 individuals diagnosed with cancer between 1986 and 1999 were selected for this study. Multivariable Cox proportional hazards regression was used to assess overall and cancer-specific death by the z-score and clinical categories of serum LDH prospectively collected within 3 years before diagnosis. Site-specific analysis was performed for major cancers. Analysis was repeated by different lag times between LDH measurements and diagnosis.

Results: At the end of follow-up, 5799 participants were deceased. Hazard ratios (HRs) and 95\% confidence intervals (Cls) for overall and cancer-specific death in the multivariable model were $1.43(1.31-1.56)$ and 1.46 (1.32-1.61), respectively, for high compared with low prediagnostic LDH. Site-specific analysis showed high LDH to correlate with an increased risk of death from prostate, pulmonary, colorectal, gastro-oesophageal, gynaecological and haematological cancers. Serum LDH assessed within intervals closer to diagnosis was more strongly associated with overall and cancer-specific death.

Conclusions: Our findings demonstrated an inverse association of baseline serum LDH with cancer-specific survival, corroborating its role in cancer progression.

\begin{abstract}
Aberrant energy metabolism is a common feature of cancer (Hanahan and Weinberg, 2011). In normal cells, when oxygen is available, pyruvate generated during the breakdown of glucose is utilised to produce energy through oxidative phosphorylation. In contrast, tumour cells prefer pyruvate metabolism via anaerobic pathway regardless of oxygen availability, leading to inefficient fuel production and formation of lactate. This anomalous metabolic preference is known as the Warburg effect or 'aerobic glycolysis' (Vander Heiden et al, 2009; Thorne and Campbell, 2014).
\end{abstract}

Lactate dehydrogenase (LDH) is the enzyme responsible for the conversion of pyruvate to lactate during glycolysis (Hirschhaeuser et al, 2011). It is expressed in all tissues and its A and B subunits, coded by two different genes $L D H-A$ and $L D H-B$, combine to construct five isoenzymes (LDH1 to LDH5) with selective distribution among tissues and in serum (Maekawa, 1988). In addition, $\mathrm{LDH}$ is known as a marker for tissue injury, inflammation, haemolysis and myocardial infarction (Drent et al, 1996; Kemp et al, 2004; Kato et al, 2006). Elevated LDH levels are

*Correspondence: Dr W Wulaningsih; E-mail: wahyu.wulaningsih@kcl.ac.uk

Received 2 August 2015; revised 14 September 2015; accepted 18 September 2015; published online 15 October 2015

(c) 2015 Cancer Research UK. All rights reserved 0007 - 0920/15 
seen in cancer patients, and its prognostic value has been shown in several malignancies such as germ cell tumours, lymphoma, melanoma and renal cell carcinoma (Balch et al, 2004; Barlow et al, 2010; Armstrong et al, 2012; Nagle et al, 2013). Most of these studies were based in hospital or clinical trial settings, with $\mathrm{LDH}$ assessed at diagnosis or after initiation of treatment. However, recent evidence linking $L D H-A$ and the oncogene $c-M Y C$ suggests that metabolic derangements may occur before the tumour becomes macroscopic, that is, before it is clinically detectable (Ferreira et al, 2012). The role of these early metabolic disturbances in the context of cancer survival remains poorly understood.

Currently, there is also a lack of information on how serum LDH contributes to cancer-specific survival in long-term follow-up (Petrelli et al, 2015). In a prospective cohort with up to 25 years of follow-up, we sought to investigate the association of prediagnostic serum LDH with overall and cancer-specific deaths among 7895 individuals diagnosed with cancer. We assessed serum LDH measured within 3 years before cancer diagnosis, during which the tumour is likely to be preclinically present (Shen and Zelen, 2001), and within 3 months before diagnosis, which represented its levels at the time of diagnosis. Furthermore, we investigated temporal associations between $\mathrm{LDH}$ and survival using $\mathrm{LDH}$ measured in different interval periods before cancer diagnosis.

\section{MATERIALS AND METHODS}

The Apolipoprotein MOrtality RISk (AMORIS) study has been described in detail elsewhere (Holme et al, 2010). Briefly, this study included Swedish men and women with blood samples sequentially sent to the Central Automation Laboratory (CALAB) in Stockholm, Sweden. This population was representative of the general Stockholm population (Holme et al, 2010). Participants were either healthy and had a laboratory testing as a part of general health check up, or were outpatients referred for laboratory testing. None of the participants were in-patients when samples were collected. In the AMORIS study, the CALAB database was linked to Swedish national registries, providing complete follow-up information. Following a recent update, the AMORIS study now includes laboratory measurements of 812073 individuals with follow-up information until 31 December 2011. From this population, we selected 7895 men and women aged $\geqslant 20$ years with histopathological diagnosis of incident cancer between 1986 and 1999 who had prediagnostic serum LDH measurements. Follow-up time was defined as the time from cancer diagnosis until the date of death from any cause, emigration or end of study (31 December 2011), whichever occurred first. The study complied with the Declaration of Helsinki and was approved by the Ethics Review Board of the Karolinska Institutet.

Diagnosis of cancer and outcomes. Cancer diagnosis was obtained from the Swedish National Cancer Register and International Classification of Diseases, 7 th revision (ICD-7) codes were used to classify major cancer sites. The outcomes of this study were overall death and cancer-specific death. The latter was based on information from the Swedish Cause of Death Register, using ICD-8 since the beginning of study until 30 December 1986, ICD-9 from 1 January 1987 to 31 December 1996 and ICD-10 codes afterwards (Supplementary Table S1). For specific cancer sites, cancer-specific deaths were defined as individuals whose primary cause of death matched their primary cancer diagnosis.

Assessment of exposure and covariates. Serum concentrations of LDH $\left(\mu \mathrm{katl}^{-1}\right)$ were measured with an enzymatic spectrophotometric method (Holme et al, 2010) on automated multichannel analyzers (an AutoChemist-PRISMA, New Clinicon, Stockholm, Sweden, 1985-1992; and a DAX 96, Technicon
Instruments Corporation, Tarrytown, NY, USA, 1993-1996) (Holme et al, 2010). Total imprecision calculated by the coefficient of variation was $<4 \%$ for both analyzers. The method was fully automated with automatic calibration and accredited laboratory facilities (Holme et al, 2010). Prediagnostic LDH was defined as the last measurement taken within 3 years before cancer diagnosis. For a secondary analysis, we collected LDH measured within six 6-month intervals before cancer diagnosis and an average was calculated for individuals with $>1$ measurement within any interval time. We calculated the standardised value ( $z$-score) of $\mathrm{LDH}$ by subtracting with the mean and dividing by the s.d. Both nontransformed LDH and its $z$-score were normally distributed. As LDH cutoffs vary across laboratories, we used its upper limit of normal (ULN) to categorise LDH into low and high levels ( $\leqslant$ ULN and $>$ ULN).

Socioeconomic status (white collar, blue collar, unemployed or unknown) was based on the national censuses (Wulaningsih et al, 2013a). We calculated Charlson comorbidity index (CCI) using information from the National Patient Register. The CCI consists of 17 groups of diseases with a specific weight assigned to each disease category (Wulaningsih et al, 2013a). These weights were then summed to obtain an overall score, resulting in four comorbidity levels $(0,1,2$ and $3+)$ indicating no comorbidity to severe comorbidity. Period of diagnosis was categorised (before 1989, 1989-1993, 1993-1997 and 1997 onwards) to account for the long period of recruitment and differences in cancer management over time. Information on tumour stage was available for 877 breast cancer cases from the Stockholm Breast Cancer Quality Register and was classified based on the American Joint Committee on Cancer (AJCC) Cancer Staging Manual 7th edition (Stages I to IV).

Statistical analysis. We used Kaplan-Meier curves to assess overall survival by categories of prediagnostic LDH, and statistical differences were assessed with the log-rank test. Cox proportional hazard regression was used to estimate hazard ratios (HRs) and their $95 \%$ confidence intervals (CIs) of overall and cause-specific death by $z$-score and categories of $\mathrm{LDH}$, adjusting for age at diagnosis. In the multivariable model, we further adjusted for sex, socioeconomic status, CCI and period of diagnosis. We also performed a site-stratified model by assigning each major cancer site as an individual stratum and the remaining cancers as one additional stratum. To assess serum $\mathrm{LDH}$ at the time of diagnosis, we repeated our analyses in a subgroup of 1657 participants who had their baseline LDH measured within 3 months before cancer diagnosis.

To observe the association between baseline $\mathrm{LDH}$ and survival in specific cancers, we performed similar multivariable analysis by major cancer sites. For breast cancer there was information available on tumour stage, and hence that we repeated this analysis while adjusting for tumour stage. Cumulative incidence functions were used to display cumulative risk of dying from all-cause and cancer, and statistical difference was assessed with Gray's test for equality of cumulative incidence functions. We displayed KaplanMeier curves and cumulative incidences only for deaths up to 10 years after diagnosis as trends past this cutoff point were similar to the ones presented. However, statistical analyses were performed using data for the whole follow-up.

In a secondary analysis, we aimed to observe any temporal association between LDH and survival in cancer patients. Pearson's correlation coefficients $(r)$ between LDH levels in different intervals were calculated. The average of LDH was measured for each 6-month time interval before cancer diagnosis and associations of LDH with overall and cancer-specific cancer survival for each lag time were examined. The models were adjusted for age at diagnosis, sex, socioeconomic status, CCI, period of diagnosis and stratified by cancer sites. A subset analysis was performed for breast cancer, stratified by tumour stage (I-II and III-IV). 
All analyses were conducted with Statistical Analysis Software (SAS) release 9.4 (SAS Institute, Cary, NC, USA) and R version 3.0.2 (R Project for Statistical Computing, Vienna, Austria).

\section{RESULTS}

Baseline characteristics of study participants by LDH categories are shown in Table 1. Mean age at diagnosis was 62 years. At the end of follow-up (mean: 8.2 years), 5799 participants (73.5\%) were deceased. Participants with high levels of baseline LDH (>ULN) were older and had higher comorbidity burden and lower 5-year overall survival rates. Distributions of serum LDH $z$-score based on characteristics of participants are available in (Supplementary Figure S1). The three most frequent cancers were breast (female), prostate and colorectal cancer.

Overall survival differed by LDH measured within 3 years before diagnosis and within 3 months before date of diagnosis, that is, $\mathrm{LDH}$ at the time at diagnosis, with lower survival seen with higher LDH (Figure 1). Correspondingly, multivariable Cox proportional hazards regression showed an increased risk of dying from all causes with higher LDH $z$-score or categories, with the HR of 1.78

Table 1. Baseline characteristics of study participants by categories of serum LDH measured within 3 years before cancer diagnosis

\begin{tabular}{|c|c|c|c|c|}
\hline & \multicolumn{4}{|c|}{ LDH } \\
\hline & \multicolumn{2}{|c|}{$\leqslant$ ULN, $\mathbf{N}(\%)$} & \multicolumn{2}{|c|}{$>$ ULN, $\mathbf{N}(\%)$} \\
\hline & No. & $\%$ & No. & $\%$ \\
\hline \multicolumn{5}{|l|}{ Age at diagnosis, years } \\
\hline Mean (s.d.) & \multicolumn{2}{|c|}{$62.3(12.7)$} & \multicolumn{2}{|c|}{$65.6(12.9)$} \\
\hline \multicolumn{5}{|l|}{ Sex, \% } \\
\hline Male & 3682 & 51.0 & 381 & 56.1 \\
\hline Female & 3534 & 49.0 & 298 & 43.9 \\
\hline \multicolumn{5}{|l|}{ Socioeconomic status, $\%$} \\
\hline White collar & 3136 & 43.5 & 237 & 34.9 \\
\hline Blue collar & 2774 & 38.4 & 147 & 36.4 \\
\hline Not gainfully employed or unknown & 1306 & 18.1 & 195 & 28.7 \\
\hline \multicolumn{5}{|l|}{ Charlson comorbidity index, \% } \\
\hline 0 & 5871 & 81.4 & 525 & 77.3 \\
\hline 1 & 871 & 12.1 & 82 & 12.1 \\
\hline 2 & 252 & 3.5 & 37 & 5.5 \\
\hline $3+$ & 222 & 3.1 & 35 & 5.2 \\
\hline \multicolumn{5}{|l|}{ Period of diagnosis, $\%$} \\
\hline Before 1989 & 1480 & 20.5 & 166 & 24.5 \\
\hline 1989-1993 & 2215 & 30.7 & 235 & 34.6 \\
\hline 1993-1997 & 2399 & 33.3 & 229 & 33.7 \\
\hline 1997 onwards & 1122 & 15.6 & 49 & 7.2 \\
\hline \multicolumn{5}{|l|}{ Cancer site, \% } \\
\hline Breast & 1081 & 15 & 37 & 5.5 \\
\hline Prostate & 832 & 11.5 & 49 & 7.2 \\
\hline Pulmonary & 598 & 8.3 & 70 & 10.3 \\
\hline Colorectal & 784 & 10.9 & 82 & 12.1 \\
\hline Gastro-oesophageal & 296 & 4.1 & 22 & 3.2 \\
\hline Hepatobiliary & 130 & 1.8 & 36 & 5.3 \\
\hline Pancreas & 222 & 3.1 & 35 & 5.2 \\
\hline Kidney & 199 & 2.8 & 25 & 3.7 \\
\hline Bladder & 335 & 4.6 & 14 & 2.1 \\
\hline Gynaecological & 486 & 6.7 & 42 & 6.2 \\
\hline Head and neck & 134 & 1.9 & 11 & 1.6 \\
\hline Melanoma & 259 & 3.6 & 13 & 1.9 \\
\hline Central nervous system & 302 & 4.2 & 14 & 2.1 \\
\hline Haematological & 567 & 7.9 & 122 & 18 \\
\hline Median survival time, months & \multicolumn{2}{|c|}{67.8} & \multicolumn{2}{|c|}{13.7} \\
\hline 5-Year overall survival, \% & \multicolumn{2}{|c|}{95.3} & \multicolumn{2}{|c|}{4.7} \\
\hline
\end{tabular}

(95\% CI: 1.64-1.94) comparing LDH levels above and below ULN. Similar findings were found when assessing cancer-specific death, for example, the HR for overall cancer death was 1.85 (95\% CI: 1.68-2.03) for high vs low $\mathrm{LDH}$. Associations were slightly attenuated when the models were stratified by cancer site (Table 2). Similar but more evident associations were found in the subanalysis only including serum $\mathrm{LDH}$ at the time at diagnosis.

When specific cancer sites were assessed, higher risk of overall death was observed with high $\mathrm{LDH}$ in individuals diagnosed with breast, prostate, pulmonary, colorectal, gastro-oesophageal, melanoma and haematological cancer and melanoma (Figure 2). The strongest association was seen for prostate cancer (HR: 2.19, 95\% CI: 1.63-2.95). Similar but weaker trends were found when assessing cancer-specific death, with a positive association between $\mathrm{LDH}$ and risk of dying from prostate, pulmonary, colorectal, gastro-oesophageal and haematological cancer. In addition, a positive association was seen with gynaecological cancer death. Results were similar when $z$-score was used (results not shown). In a subgroup analysis of 877 women with breast cancer and available information on tumour stage, adjustment for tumour stage did not alter the associations between LDH and death, with HR of all-cause and breast cancer death of 1.73 (95\% CI: 1.12-2.67) and 1.54 (95\% CI: 0.81-2.92), respectively, for high compared with low LDH levels (results not shown).

We further visualised the association between $\mathrm{LDH}$ and cancer with cumulative incidence functions (Figure 3) and found higher cumulative risks of dying from overall, prostate, pulmonary, colorectal, gastro-oesophageal, kidney, gynaecological and haematological cancer with high LDH levels. Interestingly, an inverse association was observed for head and neck cancer that approached statistical significance (Gray's test $P=0.05$ ).

In our secondary analysis, LDH levels measured within 6-month time intervals before cancer diagnosis were found to be increasing in interval times closer to diagnosis for overall and several types of cancer such as hepatobiliary and haematological cancer (Supplementary Figure S2). The LDH measurements taken within different interval times were highly correlated $(r>0.5$ and $P<0.0001$; Supplementary Table S2). When risk of overall death in all participants was assessed for every interval time, a stronger association was observed with mean $\mathrm{LDH}$ measured closer to diagnosis, that is, within 1 year before diagnosis. However, we found an increased risk of early death in those with high $\mathrm{LDH}$ measured 30 to 36 months before diagnosis (HR: 1.46, 95\% CI: 1.15-1.86). For cancer-specific death, associations were also stronger when $\mathrm{LDH}$ was measured closer to diagnosis (Table 3 ). Similarly, in patients with stage I to II breast cancer, we found a positive association between LDH measured 30 to 36 months before diagnosis and overall death (HR: 2.97, 95\% CI: 1.38-6.39), and between LDH measured 6 to 12 months before diagnosis and breast cancer death (HR: 1.95, 95\% CI: 1.24-16.00). Results in advanced stage of disease were hampered by a low number of events (results not shown).

\section{DISCUSSION}

In the present study, we found higher prediagnostic LDH to correspond to lower overall and cancer-specific survival following cancer diagnosis. More specifically, a greater risk of dying from cancer was seen with increasing LDH in those diagnosed with prostate, pulmonary, colorectal, gastro-oesophageal, gynaecological or haematological cancer. Furthermore, we found that the associations between LDH and both all-cause and overall cancer deaths were stronger when $\mathrm{LDH}$ was measured closer to cancer diagnosis. 

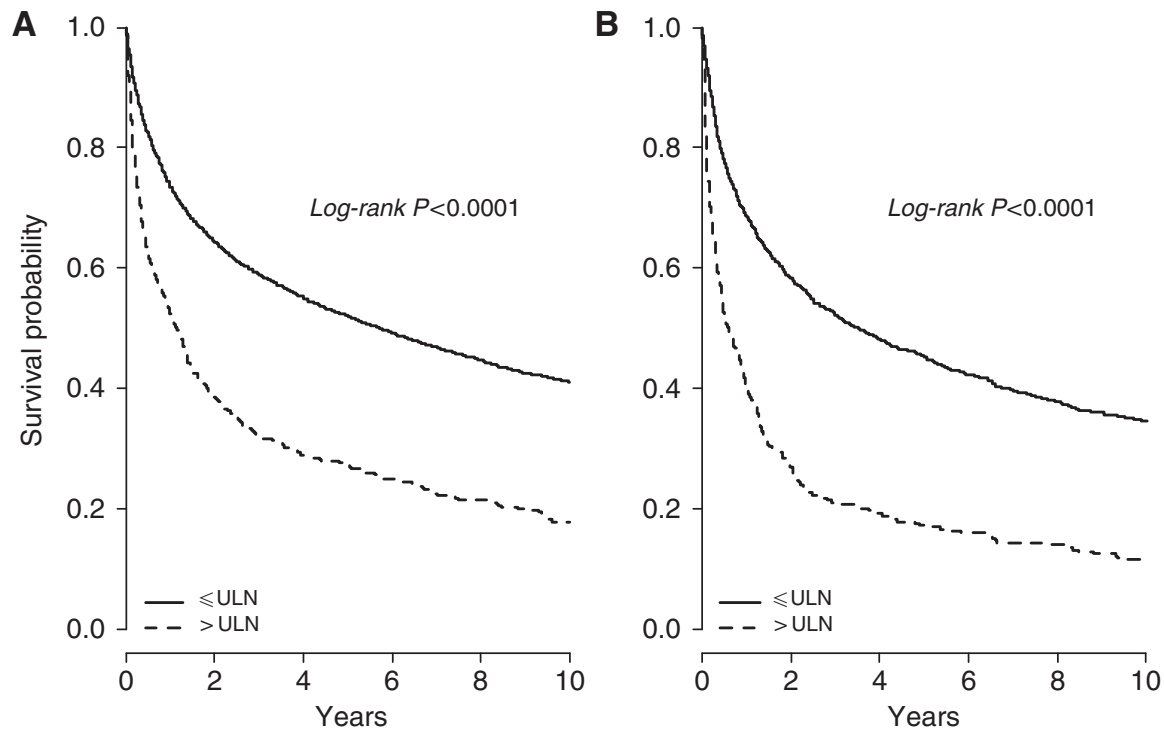

Figure 1. Kaplan-Meier curves for 10-year overall survival following cancer diagnosis by serum LDH levels measured (A) within 3 years before diagnosis and (B) within 3 months before diagnosis.

Table 2. Hazard ratios and $95 \%$ confidence intervals for associations between prediagnostic serum LDH and risk of death following cancer diagnosis

\begin{tabular}{|c|c|c|c|}
\hline & \multicolumn{3}{|c|}{ LDH } \\
\hline & Z-score & $\leqslant \mathrm{ULN}$ & $>$ ULN \\
\hline \multicolumn{4}{|l|}{ All-cause death } \\
\hline No. of deaths/all patients & & $5187 / 7216$ & $612 / 679$ \\
\hline Age adjusted & $1.18(1.16-1.21)$ & 1.0 (Ref) & $1.78(1.64-1.94)$ \\
\hline Multivariable $^{a}$ & $1.16(1.14-1.19)$ & 1.0 (Ref) & $1.66(1.53-1.81)$ \\
\hline Stratified by cancer site ${ }^{a}$ & $1.12(1.10-1.15)$ & 1.0 (Ref) & $1.43(1.31-1.56)$ \\
\hline $\begin{array}{l}\text { Sampling } \leqslant 3 \text { months } \\
\text { before diagnosis }{ }^{\mathrm{b}}\end{array}$ & $1.15(1.12-1.18)$ & 1.0 (Ref) & $1.91(1.65-2.20)$ \\
\hline \multicolumn{4}{|l|}{ Cancer-specific death } \\
\hline No. of deaths/all patients & & $3760 / 7216$ & $462 / 679$ \\
\hline Age adjusted & $1.19(1.17-1.22)$ & 1.0 (Ref) & $1.85(1.68-2.03)$ \\
\hline Multivariable ${ }^{a}$ & $1.17(1.14-1.20)$ & $1.0(\operatorname{Ref})$ & $1.72(1.56-1.90)$ \\
\hline Stratified by cancer site ${ }^{a}$ & $1.12(1.10-1.15)$ & 1.0 (Ref) & $1.46(1.32-1.61)$ \\
\hline $\begin{array}{l}\text { Sampling } \leqslant 3 \text { months } \\
\text { before diagnosis }\end{array}$ & $1.17(1.12-1.20)$ & 1.0 (Ref) & $2.06(1.76-2.41)$ \\
\hline \multicolumn{4}{|c|}{$\begin{array}{l}\text { Abbreviations: } \mathrm{LDH}=\text { lactate dehydrogenase; Ref = reference; ULN = upper limit of normal. } \\
\text { a Adjusted for age at diagnosis, sex, socioeconomic status, Charlson comorbidity index and } \\
\text { period of diagnosis. } \\
\text { b Subanalysis in } 1657 \text { participants. Adjusted for age at diagnosis, sex, socioeconomic status, } \\
\text { Charlson comorbidity index, period of diagnosis and stratified by cancer site. }\end{array}$} \\
\hline
\end{tabular}

Several plausible mechanisms may underlie the link between $\mathrm{LDH}$ and cancer progression. Rapidly proliferating cancer cells requires extreme supplies of energy and chronic hypoxia secondary to tumour growth activates hypoxia-inducible factor 1 (HIF-1), a key regulator of glycolysis and angiogenesis (Palmer and Clegg, 2014). The HIF-1 drives the metabolic switch to glycolysis by stimulating expression of glycolytic enzymes (Seagroves et al, 2001) and directly repressing mitochondrial function through activation of pyruvate dehydrogenase kinase 1 (PDK-1) (Kim et al, 2006; Papandreou et al, 2006). The subsequent accumulation of glycolytic metabolites may promote further HIF-1 activation, resulting in a feed-forward stimulatory loop in cancer cells (McFate et al, 2008). Hypoxia-inducible factor 1 also upregulates angiogenic factors including vascular endothelial growth factor-A (VEGF-A) (Pouysségur et al, 2006), therefore linking glycolysis and LDH to angiogenesis and cancer progression (Ostergaard et al, 2013; Parks et al, 2013). However, continuous oxygen availability in glycolytic cancers, such as leukaemia, suggests that other underlying factors may trigger the switch to aerobic glycolysis before hypoxia occurs (Vander Heiden et al, 2009). In addition, the tumour-promoting role of $\mathrm{A}$ and $\mathrm{B}$ subunits of $\mathrm{LDH}$ has been suggested: increased LDH-A levels are crucial in c-MYC-mediated cell transformation (Shim et al, 1997; Lewis et al, 2000), whereas LDH-B is necessary in mammalian target of rapamycin (mTOR)-mediated tumourigenesis (Zha et al, 2011). These biological findings imply that LDH may be relevant to tumour growth and severity, and may also play a role in carcinogenesis.

A prognostic value of serum LDH has been suggested in several types of cancer, particularly haematological malignancies. Serum $\mathrm{LDH}$ is a predictor of worse survival in diffuse large B-cell lymphoma (DBCL) and is one of the five risk factors included in the International Prognostic Index (IPI) (Nagle et al, 2013; Zhou et al, 2014). Similar associations with survival have been established in chronic myeloid and lymphocytic leukaemias (Weinberg et al, 2007; Goldaniga et al, 2008) and small cell lung cancer (SCLC) (You et al, 2008; Danner et al, 2010). In recent clinical trials, elevated serum $\mathrm{LDH}$ has been shown as an independent predictor of overall survival in advanced or metastatic cancer of the breast (Brown et al, 2012), prostate (Scher et al, 2009; Gravis et al, 2014), colorectum (Bar et al, 2014), oesophagus (Polee et al, 2003), pancreas (Tas et al, 2001), ovary (Schneider et al, 1998), nasopharynx (Jin et al, 2013), gastric adenocarcinoma (Sougioultzis et al, 2011), hepatocellular carcinoma (HCC) (Faloppi et al, 2014), renal cell carcinoma (Armstrong et al, 2012) and melanoma (Balch et al, 2004; Weide et al, 2012). The inverse association with overall survival in solid tumours were shown in a recent meta-analysis, with HR for overall death of 1.7 (95\% CI: 1.62-1.79) (Petrelli et al, 2015). Nevertheless, a marked publication bias was observed, with most of smaller studies reporting only positive associations. Our study also found higher risks of early death among cancer patients with high levels of baseline serum $\mathrm{LDH}$ at the time of diagnosis and within 3 years before diagnosis. However, when we performed site-specific analysis with cancer-specific death as the outcome of interest, this association was only shown in those diagnosed with prostate, pulmonary, colorectal, gastro-oesophageal, gynaecological or haematological cancer. Considering the link of $\mathrm{LDH}$ with other chronic diseases that may contribute to death (Kemp et al, 2004; Kato et al, 2006), it is therefore important to consider causespecific death to gain further insight into the prognostic relevance of $\mathrm{LDH}$. 
All-cause death

Cancer site

No. of deaths $\quad \mathrm{HR}(95 \% \mathrm{Cl})$

Breast $^{\dagger}$

Prostate $^{\ddagger}$

Pulmonary

Colorectal

Gastro-oesophageal

Hepatobiliary

Pancreas

Kidney

Bladder

Gynaecological $^{\dagger}$

Head and neck

Melanoma

Central nervous system

Haematological

${ }^{\dagger}$ Subanalysis in women; not adjusted for sex

${ }^{\ddagger}$ Subanalysis in men; not adjusted for sex
$1.76(1.21-2.57)$

$7132.19(1.63-2.95)$

647

1.74 (1.34-2.25)

681

304

165

254

183

233

323

112

104

211

$1.88(1.47-2.40)$

$0.76(0.51-1.13)$

0.94 (0.64-1.36)

$1.11(0.67-1.83)$

$1.18(0.64-2.16)$

1.42 (0.97-2.09)

$0.72(0.32-1.60)$

$2.40(1.16-5.00)$

1.64 (0.91-2.94)

1.36 (1.09-1.69)
2.08 (1.33-3.26)

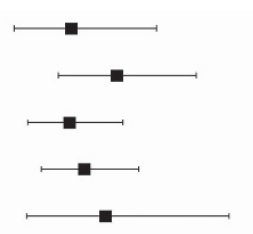

No. of deaths $\quad \operatorname{HR}(95 \% \mathrm{Cl})$

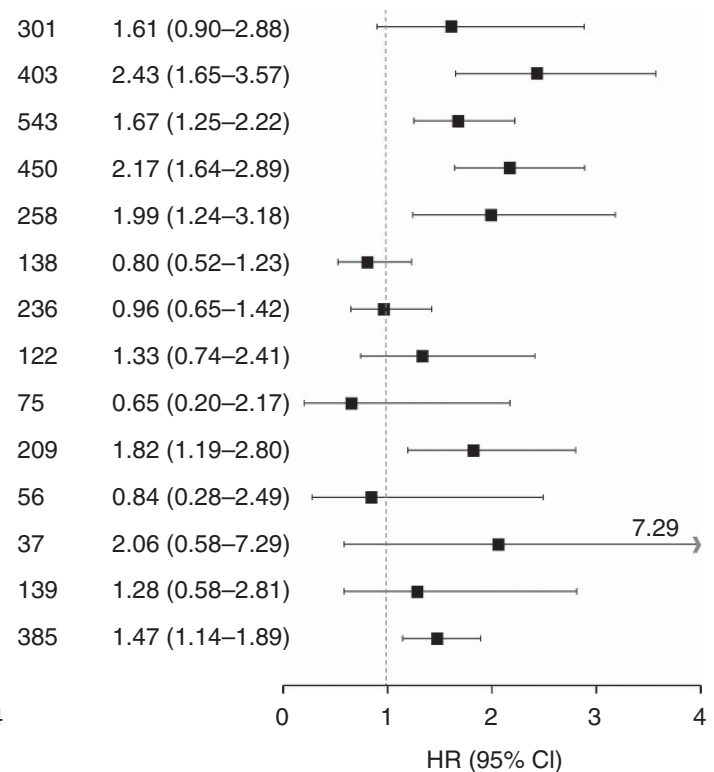

Figure 2. Hazard ratios and $95 \%$ confidence intervals for death following cancer diagnosis for high (>ULN) compared with low serum LDH $(\leqslant \mathrm{ULN})$ as the reference, stratified by cancer site. All models were adjusted for age at diagnosis, sex, socioeconomic status, Charlson comorbidity index and period of diagnosis.
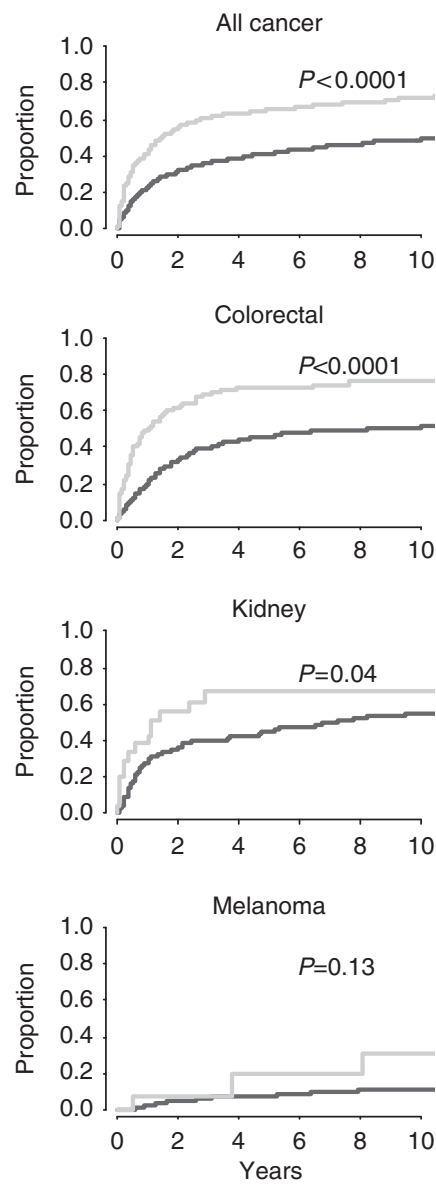
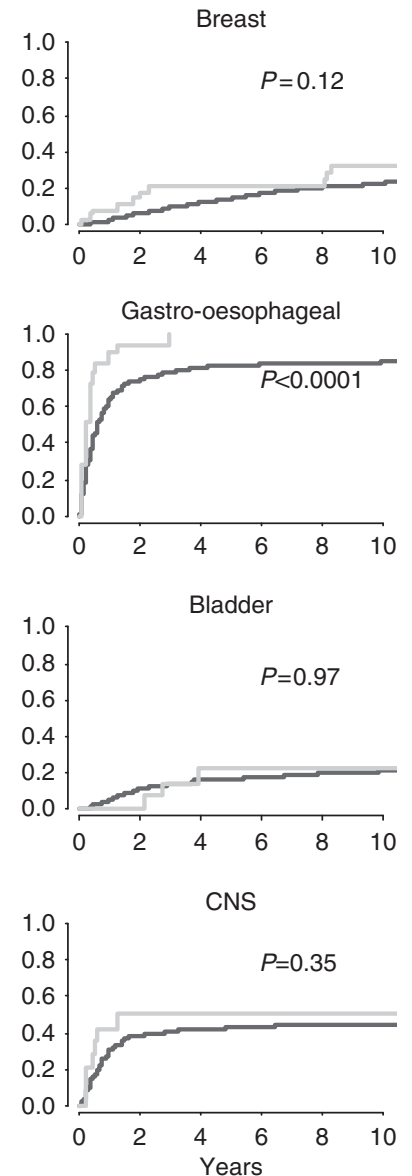
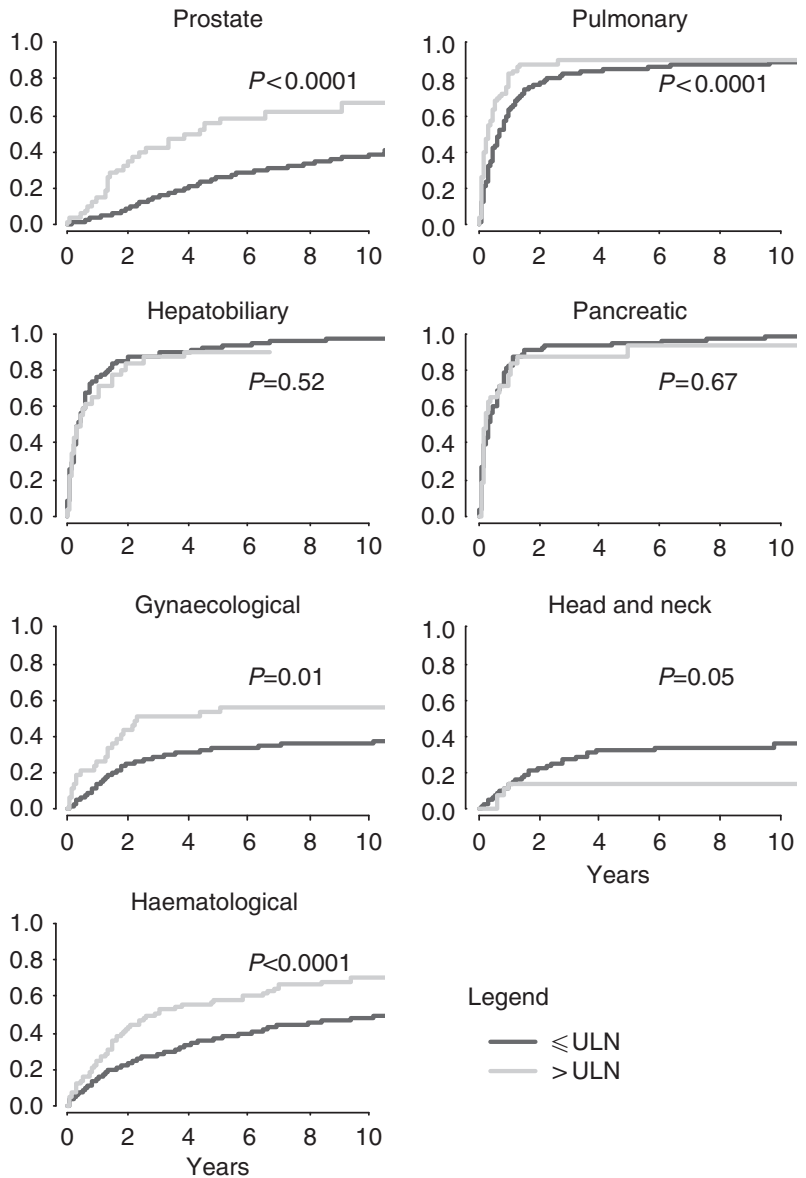

Legend

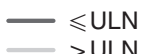

Figure 3. The 10-year cumulative incidence of cancer-specific deaths, stratified by clinical categories of serum LDH. CNS $=$ central nervous system.

We observed a borderline inverse trend between LDH and head and neck cancer death, although our analysis was limited by the number of events. The unique distribution of $\mathrm{LDH}$ subunits
(Augoff et al, 2014) may explain different associations of serum expression of $\mathrm{LDH}$ with specific cancer types. Supporting this notion, our observation of average LDH levels measured by 
Table 3. Hazard ratios and $95 \%$ confidence intervals for temporal associations between serum LDH and risk of death following cancer diagnosis

\begin{tabular}{|c|c|c|c|c|}
\hline & & \multicolumn{3}{|c|}{$\mathrm{LDH}^{\mathrm{a}}$} \\
\hline $\begin{array}{l}\text { Lag } \\
\text { time, } \\
\text { months }\end{array}$ & $\begin{array}{c}\text { No. of } \\
\text { deaths/all } \\
\text { patients }\end{array}$ & Z-score & $\leqslant$ ULN & $>$ ULN \\
\hline \multicolumn{5}{|c|}{ All-cause death } \\
\hline $0-6$ & $1952 / 2426$ & $1.14(1.11-1.17)$ & 1.0 (Ref) & 2.01 (1.79-2.25) \\
\hline $6-12$ & $1124 / 1523$ & $1.10(1.03-1.18)$ & 1.0 (Ref) & $1.48(1.21-1.83)$ \\
\hline $12-18$ & $1188 / 1620$ & $1.04(0.96-1.12)$ & 1.0 (Ref) & $1.01(0.79-1.31)$ \\
\hline $18-24$ & $1176 / 1589$ & 1.10 (1.02-1.18) & 1.0 (Ref) & $1.23(0.96-1.57)$ \\
\hline $24-30$ & $1287 / 1750$ & $1.04(0.96-1.13)$ & 1.0 (Ref) & $1.16(0.90-1.51)$ \\
\hline $30-36$ & 1300/1818 & 1.10 (1.01-1.19) & 1.0 (Ref) & $1.46(1.15-1.86)$ \\
\hline \multicolumn{5}{|c|}{ Cancer-specific death } \\
\hline $0-6$ & $1498 / 2426$ & $1.15(1.12-1.18)$ & 1.0 (Ref) & $2.11(1.86-2.40)$ \\
\hline $6-12$ & $801 / 1523$ & $1.11(1.02-1.20)$ & 1.0 (Ref) & $1.54(1.21-1.96)$ \\
\hline $12-18$ & $839 / 1620$ & $1.04(0.95-1.15)$ & 1.0 (Ref) & $1.08(0.80-1.47)$ \\
\hline $18-24$ & $837 / 1589$ & 1.07 (0.98-1.17) & 1.0 (Ref) & 1.07 (0.79-1.46) \\
\hline $24-30$ & $913 / 1750$ & $0.99(0.90-1.10)$ & 1.0 (Ref) & $0.97(0.68-1.38)$ \\
\hline $30-36$ & $906 / 1818$ & $1.04(0.94-1.15)$ & 1.0 (Ref) & $1.10(0.80-1.52)$ \\
\hline \multicolumn{5}{|c|}{ 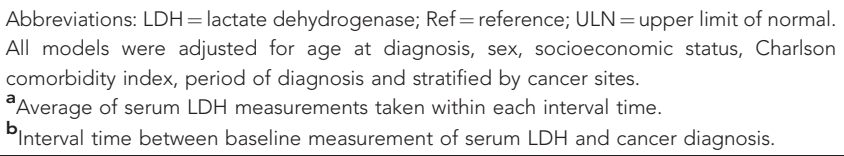 } \\
\hline
\end{tabular}

6-month intervals before diagnosis showed varying trends across different cancer sites that may indicate a different extent of aerobic glycolysis with respect to cancer types. It is known that the majority of LDH subunits detected in the serum is LDH-B, although LDH-A exists in a lesser amount (Maekawa, 1988). The absence of $L D H-B$ expression and its enzyme activities have been reported in cell lines of breast (Brown et al, 2013), prostate (Leiblich et al, 2006), gastric and pancreatic cancer (Maekawa et al, 2003), suggested to be driven by promoter hypermethylation. As LDH-B kinetically favours the backward reaction of pyruvatelactate conversion (Augoff et al, 2014), this may suggest that LDHA, which mostly catalyses the formation of lactate, is more relevant to cancer than LDH-B (Maekawa, 1988). However, recent evidence has shown that higher tissue expression of LDH-B correlates to overall survival in lung cancer and treatment response in breast cancer (Dennison et al, 2013; McCleland et al, 2013), highlighting the role of LDH-B in cancer progression. Given the scarcity of data regarding the long-term impact of differential LDH expression on cancer survival, further investigations are needed to confirm the clinical usefulness of $\mathrm{LDH}$ with respect to its subunits or isoenzymes.

In addition to the positive association between prediagnostic $\mathrm{LDH}$ and death following cancer diagnosis, we were able to demonstrate the importance of timing in $\mathrm{LDH}$ measurement. Lactate dehydrogenase measured within 12 months before the diagnosis of cancer was shown to be strongly associated with overall and cancer-specific death, further indicating the relevance between $\mathrm{LDH}$ and tumour growth or severity. The positive association between LDH measured within 30 to 36 months before diagnosis and risk of overall as well as breast cancer death further signifies the importance of assessing cancer-specific death, especially because higher $\mathrm{LDH}$ is also linked to cardiovascular disease and mortality (Savory and Pryce, 1980; Kemp et al, 2004).

The strengths of our study included the prospectively collected serum LDH before the diagnosis of cancer. Complete follow-up was obtained and all laboratory measurements were performed in the same laboratory (Holme et al, 2010). Although a number of studies have indicated the association between LDH and overall survival (Petrelli et al, 2015), this is the first populationbased study linking baseline $\mathrm{LDH}$ and cancer-specific survival.
A limitation of our study is the lack of information on cancer treatment, and given the long period of recruitment (1986-1999), variation in management of cancer may affect timing of cancer diagnosis and its survival. We therefore accounted for period of diagnosis in our analyses as a proxy for difference in screening and treatment over time. Information on race/ethnicity was not available; however, the AMORIS cohort was similar to the general working population of Stockholm (Wulaningsih et al, 2013b) that comprised $\sim 80 \%$ Swedish-born individuals in 2000 (Statistics Sweden, 2015). Serum LDH increases because of other conditions such as myocardial infarction, inflammation and tissue injury (Drent et al, 1996; Kemp et al, 2004; Kato et al, 2006), and therefore is not a specific marker of tumour. Higher LDH at baseline may otherwise indicate inflammation or other disorders involved in pathways leading to cancer development. However, we limited our analysis to 3 years before diagnosis to exclude reverse causation and adjusted for CCI in the analysis to take into account other diseases that may have predisposed one to worse survival. Nevertheless, residual confounding may occur. In addition, we did not have information on LDH subunits or isoenzymes and tumour characteristics such as stage, receptor status and histological grade. However, associations between $\mathrm{LDH}$ and all-cause or specific cancer death in breast cancer patients were not affected by tumour stage. For several cancers such as lymphoma, the combination between serum LDH and tumour characteristics shows to be useful in predicting treatment response and prognosis (Zhou et al, 2014). Thus, extrapolating our findings to clinic may require similar combination approaches with other biological markers in order to identify patients at higher risks of dying from cancer.

\section{CONCLUSION}

Based on prospectively collected serum LDH, our study demonstrated an inverse association between LDH and survival following cancer diagnosis, adding to the current evidence on the role of $\mathrm{LDH}$ in cancer progression. Future mechanistic studies are therefore necessary to establish whether serum LDH is a proxy of tumour growth and severity, which explains its association to cancer survival, or whether it is also involved in early carcinogenesis.

\section{ACKNOWLEDGEMENTS}

The research was funded/supported by the National Institute for Health Research (NIHR) Biomedical Research Centre based at Guy's and St Thomas' NHS Foundation Trust and King's College London. The views expressed are those of the author(s) and not necessarily those of the NHS, the NIHR or the Department of Health.

\section{CONFLICT OF INTEREST}

Niklas Hammar is employed by AstraZeneca. However, the views expressed in this study are his own and not those of AstraZeneca. The remaining authors declare no conflict of interest.

\section{REFERENCES}

Armstrong AJ, George DJ, Halabi S (2012) Serum lactate dehydrogenase predicts for overall survival benefit in patients with metastatic renal cell carcinoma treated with inhibition of mammalian target of rapamycin. J Clin Oncol 30: 3402-3407. 
Augoff K, Hryniewicz-Jankowska A, Tabola R (2014) Lactate dehydrogenase 5: an old friend and a new hope in the war on cancer. Cancer Lett 358(1): $1-7$.

Balch CM, Soong S, Atkins MB, Buzaid AC, Cascinelli N, Coit DG, Fleming ID, Gershenwald JE, Houghton A, Kirkwood JM, McMasters KM, Mihm MF, Morton DL, Reintgen DS, Ross MI, Sober A, Thompson JA, Thompson JF (2004) An evidence-based staging system for cutaneous melanoma. CA Cancer J Clin 54: 131-149quiz 182-184.

Bar J, Spencer S, Morgan S, Brooks L, Cunningham D, Robertson J, Jürgensmeier JM, Goss GD (2014) Correlation of lactate dehydrogenase isoenzyme profile with outcome in patients with advanced colorectal cancer treated with chemotherapy and bevacizumab or cediranib: retrospective analysis of the HORIZON I study. Clin Colorectal Cancer 13: 46-53.

Barlow LJ, Badalato GM, McKiernan JM (2010) Serum tumor markers in the evaluation of male germ cell tumors. Nat Rev Urol 7: 610-617.

Brown JE, Cook RJ, Lipton A, Coleman RE (2012) Serum lactate dehydrogenase is prognostic for survival in patients with bone metastases from breast cancer: a retrospective analysis in bisphosphonate-treated patients. Clin Cancer Res 18: 6348-6355.

Brown NJ, Higham SE, Perunovic B, Arafa M, Balasubramanian S, Rehman I (2013) Lactate dehydrogenase-B is silenced by promoter methylation in a high frequency of human breast cancers. PLoS One 8: e57697.

Danner BC, Didilis VN, Wiemeyer S, Stojanovic T, Kitz J, Emmert A, Füzesi L, Schöndube FA (2010) Long-term survival is linked to serum LDH and partly to tumour LDH-5 in NSCLC. Anticancer Res 30: 1347-1351.

Dennison JB, Molina JR, Mitra S, González-Angulo AM, Balko JM, Kuba MG, Sanders ME, Pinto Ja, Gómez HL, Arteaga CL, Brown RE, Mills GB (2013) Lactate dehydrogenase B: a metabolic marker of response to neoadjuvant chemotherapy in breast cancer. Clin Cancer Res 19: 3703-3713.

Drent M, Cobben NA, Henderson RF, Wouters EF, van Dieijen-Visser M (1996) Usefulness of lactate dehydrogenase and its isoenzymes as indicators of lung damage or inflammation. Eur Respir J 9: 1736-1742.

Faloppi L, Scartozzi M, Bianconi M, Svegliati Baroni G, Toniutto P, Giampieri R, Del Prete M, De Minicis S, Bitetto D, Loretelli C, D’Anzeo M, Benedetti A, Cascinu S (2014) The role of LDH serum levels in predicting global outcome in HCC patients treated with sorafenib: implications for clinical management. BMC Cancer 14: 110.

Ferreira LMR, Hebrant A, Dumont JE (2012) Metabolic reprogramming of the tumor. Oncogene 31: 3999-4011.

Goldaniga M, Ferrario A, Cortelazzo S, Guffanti A, Pavone E, Ambrosetti A, Marcheselli L, Rossi F, Luminari S, Rossi A, Cro L, Federico M, Lambertenghi Deliliers G, Baldini L (2008) A multicenter retrospective clinical study of CD5/CD10-negative chronic B cell leukemias. Am J Hematol 83: 349-354.

Gravis G, Boher J-M, Fizazi K, Joly F, Priou F, Marino P, Latorzeff I, Delva R, Krakowski I, Laguerre B, Walz J, Rolland F, Théodore C, Deplanque G, Ferrero J-M, Pouessel D, Mourey L, Beuzeboc P, Zanetta S, Habibian M, Berdah J-F, Dauba J, Baciuchka M, Platini C, Linassier C, Labourey J-L, Machiels JP, Kouri C, El, Ravaud A, Suc E, Eymard J-C, Hasbini A, Bousquet G, Soulie M, Oudard S (2014) Prognostic factors for survival in noncastrate metastatic prostate cancer: validation of the Glass Model and development of a novel simplified prognostic model. Eur Urol 68(2): 196-204.

Hanahan D, Weinberg RA (2011) Hallmarks of cancer: the next generation. Cell 144: 646-674.

Hirschhaeuser F, Sattler UGa, Mueller-Klieser W (2011) Lactate: a metabolic key player in cancer. Cancer Res 71: 6921-6925.

Holme I, Aastveit AH, Hammar N, Jungner I, Walldius G (2010) Inflammatory markers, lipoprotein components and risk of major cardiovascular events in 65,005 men and women in the Apolipoprotein MOrtality RISk study (AMORIS). Atherosclerosis 213: 299-305.

Jin Y, Ye X, Shao L, Lin BC, He CX, Zhang BB, Zhang YP (2013) Serum lactic dehydrogenase strongly predicts survival in metastatic nasopharyngeal carcinoma treated with palliative chemotherapy. Eur J Cancer 49: $1619-1626$.

Kato GJ, McGowan V, Machado RF, Little JA, Taylor VIJ, Morris CR, Nichols JS, Wang X, Poljakovic M, Morris SM, Gladwin MT (2006) Lactate dehydrogenase as a biomarker of hemolysis-associated nitric oxide resistance, priapism, leg ulceration, pulmonary hypertension, and death in patients with sickle cell disease. Blood 107: 2279-2285.

Kemp M, Donovan J, Higham H, Hooper J (2004) Biochemical markers of myocardial injury. Br J Anaesth 93: 63-73.
Kim J, Tchernyshyov I, Semenza GL, Dang CV (2006) HIF-1-mediated expression of pyruvate dehydrogenase kinase: a metabolic switch required for cellular adaptation to hypoxia. Cell Metab 3: 177-185.

Leiblich A, Cross SS, Catto JWF, Phillips JT, Leung HY, Hamdy FC, Rehman I (2006) Lactate dehydrogenase-B is silenced by promoter hypermethylation in human prostate cancer. Oncogene 25: 2953-2960.

Lewis BC, Prescott JE, Campbell SE, Shim H, Orlowski RZ, Dang CV (2000) Tumor induction by the c-Myc target genes $\mathrm{rcl}$ and lactate dehydrogenase A. Cancer Res 60: 6178-6183.

Maekawa M (1988) Lactate dehydrogenase isoenzymes. J Chromatogr 429: 373-398.

Maekawa M, Taniguchi T, Ishikawa J, Sugimura H, Sugano K, Kanno T (2003) Promoter hypermethylation in cancer silences LDHB, eliminating lactate dehydrogenase isoenzymes 1-4. Clin Chem 49: 1518-1520.

McCleland ML, Adler AS, Deming L, Cosino E, Lee L, Blackwood EM, Solon M, Tao J, Li L, Shames D, Jackson E, Forrest WF, Firestein R (2013) Lactate dehydrogenase $\mathrm{B}$ is required for the growth of KRAS-dependent lung adenocarcinomas. Clin Cancer Res 19: 773-784.

McFate T, Mohyeldin A, Lu H, Thakar J, Henriques J, Halim ND, Wu H, Schell MJ, Tsang TM, Teahan O, Zhou S, Califano Ja, Jeoung NH, Harris Ra, Verma A (2008) Pyruvate dehydrogenase complex activity controls metabolic and malignant phenotype in cancer cells. J Biol Chem 283: 22700-22708.

Nagle SJ, Woo K, Schuster SJ, Nasta SD, Stadtmauer E, Mick R, Svoboda J (2013) Outcomes of patients with relapsed/refractory diffuse large B-cell lymphoma with progression of lymphoma after autologous stem cell transplantation in the rituximab era. Am J Hematol 88: 890-894.

Ostergaard L, Tietze A, Nielsen T, Drasbek KR, Mouridsen K, Jespersen SN, Horsman MR (2013) The relationship between tumor blood flow, angiogenesis, tumor hypoxia, and aerobic glycolysis. Cancer Res 73: 5618-5624.

Palmer BF, Clegg DJ (2014) Oxygen sensing and metabolic homeostasis. Mol Cell Endocrinol 397: 51-58.

Papandreou I, Cairns Ra, Fontana L, Lim AL, Denko NC (2006) HIF-1 mediates adaptation to hypoxia by actively downregulating mitochondrial oxygen consumption. Cell Metab 3: 187-197.

Parks SK, Chiche J, Pouysségur J (2013) Disrupting proton dynamics and energy metabolism for cancer therapy. Nat Rev Cancer 13: 611-623.

Petrelli F, Cabiddu M, Coinu A, Borgonovo K, Ghilardi M, Lonati V, Barni S (2015) Prognostic role of lactate dehydrogenase in solid tumors: a systematic review and meta-analysis of 76 studies. Acta Oncol 54: 961-970.

Polee MB, Hop WCJ, Kok TC, Eskens FA, van der Burg MEL, Splinter TaW, Siersema PD, Tilanus HW, Stoter G, van der Gaast A (2003) Prognostic factors for survival in patients with advanced oesophageal cancer treated with cisplatin-based combination chemotherapy. Br J Cancer 89: 2045-2050.

Pouysségur J, Dayan F, Mazure NM (2006) Hypoxia signalling in cancer and approaches to enforce tumour regression. Nature 441: 437-443.

Savory DJ, Pryce JD (1980) Prognostic significance of LDH activity in ischaemic heart disease. Lancet 2: 1375-1376.

Scher HI, Jia X, de Bono JS, Fleisher M, Pienta KJ, Raghavan D, Heller G (2009) Circulating tumour cells as prognostic markers in progressive, castration-resistant prostate cancer: a reanalysis of IMMC38 trial data. Lancet Oncol 10: 233-239.

Schneider D, Halperin R, Halperin D, Bukovsky I, Hadas E (1998) Prediction of the survival of patients with advanced ovarian cancer according to a risk model based on a scoring system. Eur J Gynaecol Oncol 19: 547-552.

Seagroves TN, Ryan HE, Lu H, Wouters BG, Knapp M, Thibault P, Laderoute K, Johnson RS (2001) Transcription factor HIF-1 is a necessary mediator of the pasteur effect in mammalian cells. Mol Cell Biol 21: 3436-3444.

Shen Y, Zelen M (2001) Screening sensitivity and sojourn time from breast cancer early detection clinical trials: mammograms and physical examinations. J Clin Oncol 19: 3490-3499.

Shim H, Dolde C, Lewis BC, Wu CS, Dang G, Jungmann RA, Dalla-Favera R, Dang CV (1997) c-Myc transactivation of LDH-A: implications for tumor metabolism and growth. Proc Natl Acad Sci USA 94: 6658-6663.

Sougioultzis S, Syrios J, Xynos ID, Bovaretos N, Kosmas C, Sarantonis J, Dokou A, Tzivras D, Zografos G, Felekouras E, Papalambros E, Tsavaris N (2011) Palliative gastrectomy and other factors affecting overall survival in stage IV gastric adenocarcinoma patients receiving chemotherapy: a retrospective analysis. Eur J Surg Oncol 37: 312-318.

Statistics Sweden (2015) http://www.scb.se/en_/ (accessed: 02/07/2015). 
Tas F, Aykan F, Alici S, Kaytan E, Aydiner A, Topuz E (2001) Prognostic factors in pancreatic carcinoma: serum LDH levels predict survival in metastatic disease. Am J Clin Oncol 24: 547-550.

Thorne JL, Campbell MJ (2014) Nuclear receptors and the Warburg effect in cancer. Int J Cancer 00: 1-9.

Vander Heiden MG, Cantley LC, Thompson CB (2009) Understanding the Warburg effect: the metabolic requirements of cell proliferation. Science 324: 1029-1033.

Weide B, Elsässer M, Büttner P, Pflugfelder A, Leiter U, Eigentler TK, Bauer J, Witte M, Meier F, Garbe C (2012) Serum markers lactate dehydrogenase and $\mathrm{S} 100 \mathrm{~B}$ predict independently disease outcome in melanoma patients with distant metastasis. Br J Cancer 107: 422-428.

Weinberg JB, Volkheimer AD, Chen Y, Beasley BE, Jiang N, Lanasa MC, Friedman D, Vaccaro G, Rehder CW, Decastro CM, Rizzieri DA, Diehl LF, Gockerman JP, Moore JO, Goodman BK, Levesque MC (2007) Clinical and molecular predictors of disease severity and survival in chronic lymphocytic leukemia. Am J Hematol 82: 1063-1070.

Wulaningsih W, Michaelsson K, Garmo H, Hammar N, Jungner I, Walldius G, Holmberg L, Van Hemelrijck M (2013a) Inorganic phosphate and the risk of cancer in the Swedish AMORIS study. BMC Cancer 13: 257.

Wulaningsih W, Michaelsson K, Garmo H, Hammar N, Jungner I, Walldius G, Lambe M, Holmberg L, Van Hemelrijck M (2013b) Serum calcium and risk of gastrointestinal cancer in the Swedish AMORIS study. BMC Public Health 13: 663.

You B, Tranchand B, Girard P, Falandry C, Ribba B, Chabaud S, Souquet P-J, Court-Fortune I, Trillet-Lenoir V, Fournel C, Tod M, Freyer G (2008)

Etoposide pharmacokinetics and survival in patients with small cell lung cancer: a multicentre study. Lung Cancer 62: 261-272.

Zha X, Wang F, Wang Y, He S, Jing Y, Wu X, Zhang H (2011) Lactate dehydrogenase $\mathrm{B}$ is critical for hyperactive mTOR-mediated tumorigenesis. Cancer Res 71: 13-18.

Zhou Z, Sehn LH, Rademaker AW, Gordon LI, Lacasce AS, CrosbyThompson A, Vanderplas A, Zelenetz AD, Abel GA, Rodriguez MA, Nademanee A, Kaminski MS, Czuczman MS, Millenson M, Niland J, Gascoyne RD, Connors JM, Friedberg JW, Winter JN (2014) An enhanced International Prognostic Index (NCCN-IPI) for patients with diffuse large B-cell lymphoma treated in the rituximab era. Blood 123: 837-842.

This work is published under the standard license to publish agreement. After 12 months the work will become freely available and the license terms will switch to a Creative Commons AttributionNonCommercial-Share Alike 4.0 Unported License.

Supplementary Information accompanies this paper on British Journal of Cancer website (http://www.nature.com/bjc) 